\title{
Graves Thyrotoxicosis and Cerebral Venous Sinus Thrombosis Causality or Chance Alone?
}

\author{
Richmond Ronald Gomes* \\ Associate Professor, Medicine, Ad-din Women's Medical College Hospital, Bangladesh
}

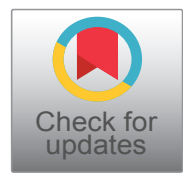

*Corresponding author: Dr. Richmond Ronald Gomes, Associate Professor of Medicine, Ad-din Women's Medical College Hospital, Dhaka, Bangladesh, Tel: 8801819289499

\begin{abstract}
Cerebral Venous Sinus Thrombosis (CVST) is a rare cerebrovascular condition accounting for $0.5-1 \%$ of all types of strokes in the general population and $12.5 \%$ of cases are considered to be idiopathic. Hypercoagulability, local bloodstream stasis, and vessel wall abnormalities may contribute to the development of this condition. The thyrotoxic phase of Graves' disease is associated with venous thrombosis caused by hypercoagulability, which is in turn induced by increased levels of homocysteine and factor VIII and decreased fibrinolytic activity. Here, we report the case of a 22-years-old female who presented with left transverse sinus thrombosis and concomitant graves thyrotoxicosis. Early diagnosis and prompt treatment of CVST are important to improve prognosis; therefore, CVST should be considered in the differential diagnosis in all patients with hyperthyroidism presenting with neurological symptoms. Cases reported in the literature suggest that the causative relationship between both is significantly higher than would be expected by chance alone.
\end{abstract}

\section{Keywords}

Graves disease, Thyrotoxicosis, Hypercoagulability, Cerebral venous sinus thrombosis, Stroke

\section{Introduction}

Cerebral Venous Sinus Thrombosis (CVST) is often categorized as a distinct subgroup of cerebrovascular disease, showing an estimated incidence of $0.5-1 \%$ of all kinds of strokes in the general population [1]. CVST is associated with various conditions that result in a hypercoagulable state and known risk factors of CVST are hereditary or acquired thrombophilia, pregnancy, puerperium, and use of oral contraceptives [2] while the less common include local infections and mechanical causes. Whereas, more than one risk factor is detectable in many patients with CVST, a relevant proportion of $12.5 \%$ of cases remains in which no risk factor is identified at all [3]. Hyperthyroidism is a predisposing factor in approximately $1.7 \%$ of patients with CVST [4]. Due to a hypercoagulable state [5,6]. Possible associations between thyrotoxicosis and CVST have been described in several case reports [7-10]. However, few studies have investigated the pathophysiology of this condition or established a definitive association because of methodological limitations.

\section{Case Report}

A 23-year-old women, not known to have hypertension, diabetes mellitus or bronchial asthma presented following several episodes of generalized tonic clonic seizures over preceding ten days. She reported several months' history of recurrent morning dull headache with vomiting. She denied any limb weakness, altered sensorium, fever, visual, and speech or memory disturbances. She also reported short-term use of medications for suspected vascular headache with amitriptyline and propranolol but there was no recent history of oral contraceptive use. When questioned, the patient reported both a loss of approximately 8-10 kg in weight, palpitations and hyperhydrosis over the previous year without loss of appetite. A physical examination revealed bilateral grade II/IV papilloedema at eye fundus, with no other neurological focal signs. Heart rate was 102 beats per minute and regular, Blood pressure was $110 / 75 \mathrm{~mm}$ of $\mathrm{Hg}$. There was a diffuse goiter without bruit. Fine distal tremors of both hands were present. There were warm, sweaty palms with

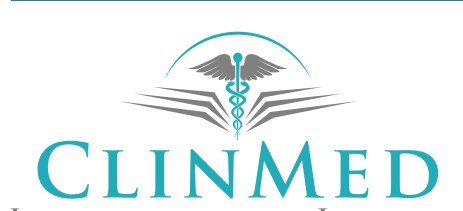

INTERNATIONAL LIBRARY 


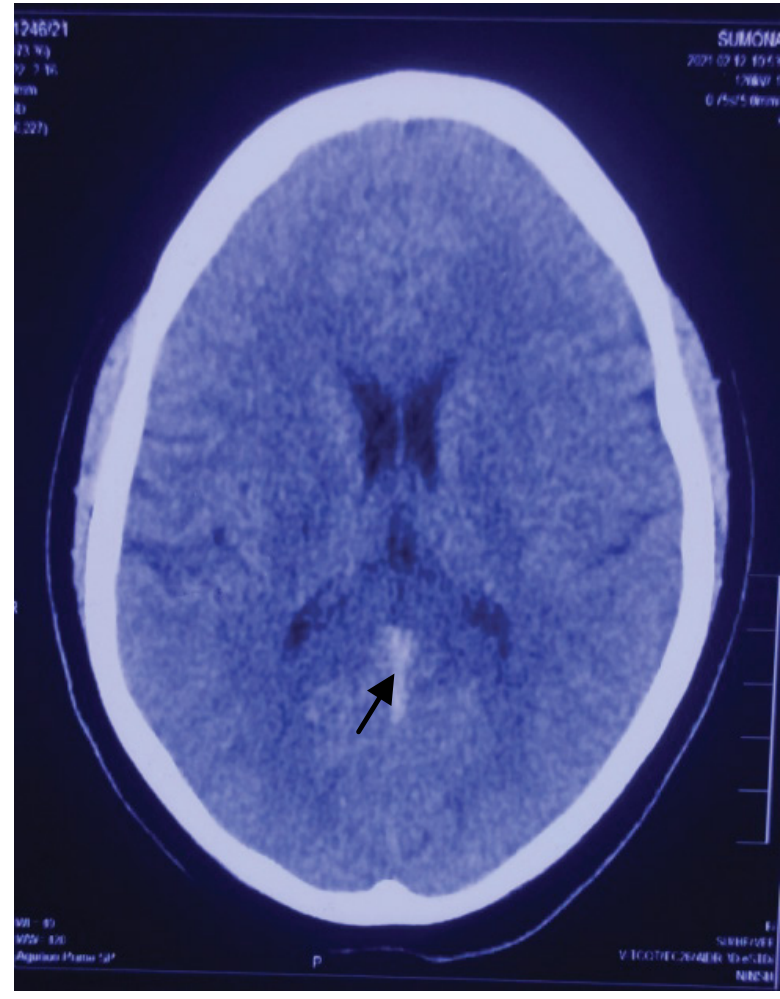

Figure 1: CT brain showing dense vein/triangle sign (arrow head).

palmar erythema. Clubbing or onycholysis were absent. There were no signs of ophthalmopathy, dermopathy or thyroid acropachy.

Initial laboratory investigations revealed normal blood counts, as well as kidney and liver function. Electrocardiography revealed sinus tachycardia. Thyroid function tests revealed a serum Thyroid-Stimulating Hormone (TSH) level $<0.004 \mu \mathrm{IU} / \mathrm{mL}$ (normal 0.350 $5.50 \mu \mathrm{IU} / \mathrm{mL}$ ), free thyroxine $\left(\mathrm{FT}_{4}\right) 4.2 \mathrm{ng} / \mathrm{dL}$ (normal 0.7-1.8 ng/dL), and free tri-iodothyronine $\left(\mathrm{FT}_{3}\right)-6.45$ $\mathrm{ng} / \mathrm{dL}$ (1.4-4.2 ng/dL). Anti-thyroid peroxidase (antiTPO) was $>2000 \mathrm{lU} / \mathrm{mL}$ (normal 5-20 IU/mL). TSHreceptor $A b$ was $59.4 \%$ (normal $<16 \%$ ) Thyroglobulin antibody $(A b)$ was within normal limit. Tests for other autoimmunity markers (antinuclear, ENA profile, ANCA) were negative. Laboratory tests performed for the assessment of a hypercoagulable state revealed the following results:, d-dimer $5.74 \mu \mathrm{g} / \mathrm{mL}$ (normal < $0.55 \mu \mathrm{g} / \mathrm{mL}$ ), fibrinogen $554.5 \mathrm{mg} / \mathrm{dL}$ (normal 200$400 \mathrm{mg} / \mathrm{dL}$ ). No changes were found in any other proteins tested (antithrombin III, protein C, protein $\mathrm{S}$, Factor $\mathrm{V}$ Leiden, von Willebrand factor, lupus anti coagulant, anti cardiolipin antibody, homocysteine). Factor VIII level was not done due to unavailability. Brain Computed Tomography (CT) revealed dense triangle/vein sign (Figure 1). Brain Magnetic Resonance Imaging (MRI) with Magnetic Resonance Venography (MRV) was performed which revealed CVST involving right transverse, right sigmoid sinus and straight sinus resulting in small acute infarct in mid part of splenium of corpus callosum (Figure 2). Ultrasonography of thyroid

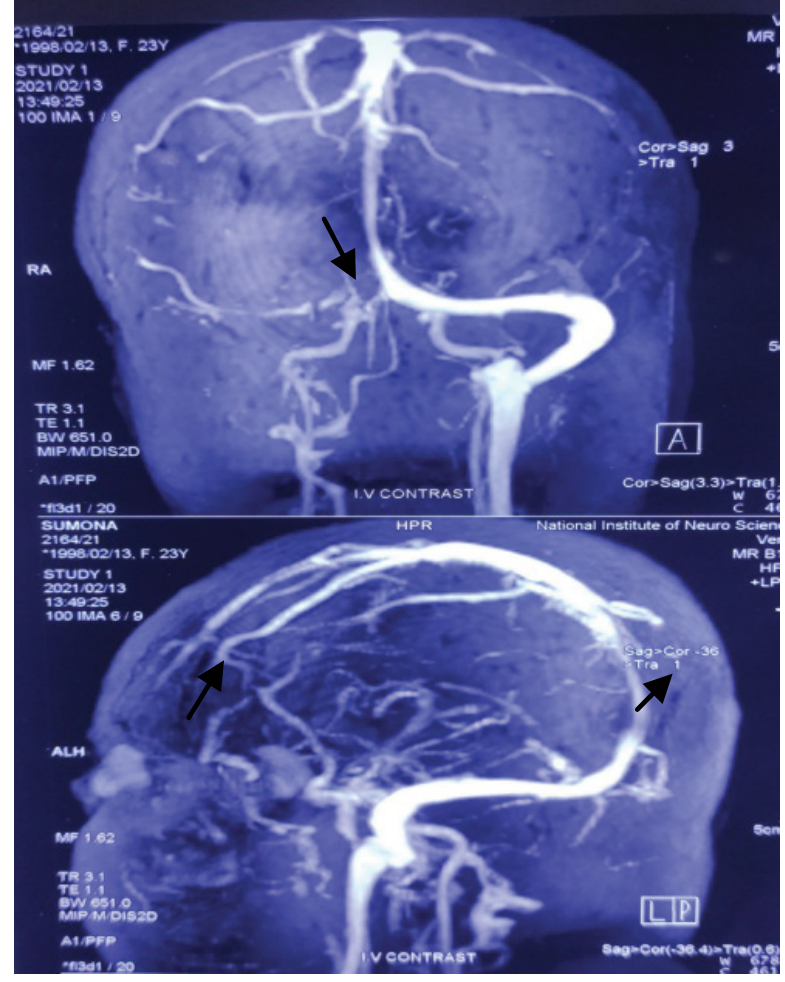

Figure 2: CT brain showing filling defect in right transverse, sigmoid and straight sinus (arrow head) suggestive of CVST.

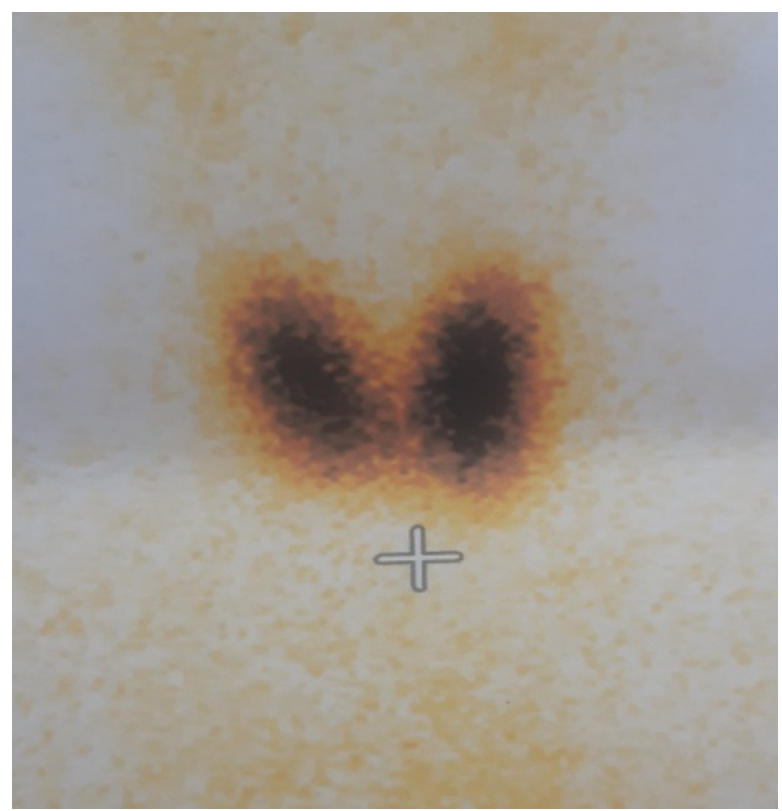

Figure 3: Thyroid scan showing diffuse homogenous uptake of radioactive tracer in both thyroid lobes suggestive of Graves disease.

revealed diffuse enlargement of both thyroid lobe with increased vascularity. Thyroid scan revealed diffuse homogenous uptake of radioactive tracer in both thyroid lobes suggestive of Graves disease (Figure 3).

Cerebral venous sinus thrombosis secondary to graves thyrotoxicosis was suspected, and treatment was started with carbimazole $30 \mathrm{mg}$ daily, low molecular weight heparin (enoxaparin $60 \mathrm{mg}$ twice daily) along 
with warfarin $5 \mathrm{mg}$ once daily. Enoxaparin was continued for seven days. After achieving target INR level of more than 2.5 for two days enoxaparin was discontinued and the patient was discharged with carbimazole and warfarin with relevant dietary advice regarding drug adverse effects. On discharge her INR was 2.62.

At the time of her outpatient follow-up after six weeks, physical and laboratory examination did not reveal any abnormal neurological findings, and she maintained a euthyroid state. Hormone values were serum Thyroid-Stimulating Hormone (TSH) level $1.2 \mu \mathrm{lU} /$ $\mathrm{mL}$ (normal 0.350-5.50 $\mu \mathrm{lU} / \mathrm{mL}$ ), free thyroxine $\left(\mathrm{FT}_{4}\right) 1.3$ $\mathrm{ng} / \mathrm{dL}$ (normal $0.7-1.8 \mathrm{ng} / \mathrm{dL}$ ), and free tri-iodothyronine $\left(\mathrm{FT}_{3}\right)-3.29 \mathrm{ng} / \mathrm{dL}(1.4-4.2 \mathrm{ng} / \mathrm{dL})$.

\section{Discussion}

CVST is categorized as a distinct subgroup of uncommon cerebrovascular disease, showing an incidence of approximately $0.5-1 \%$ of all kinds of strokes in the general population [1] with mortality rate is about 5\% [11]. CVST is associated with various conditions that result in a hypercoagulable state. The possible underlying causes or risk factors span a broad spectrum of conditions. These range from focal-like infections of the central nervous system, as well as traumas or arteriovenous malformations to systemic disorders such as cancer, hematological disorders or prothrombotic conditions, both genetic and acquired. Along with oral contraceptives, the latter represent the most common risk factors. Several case reports, small clinical trials and basic research studies generally suggest that thyroid diseases, especially hyperthyroidism, serve as a risk factor for CVST or thromboembolism. Existing data indicate a possible association between hyperthyroidism and moderate hypothyroidism with a state of hypercoagulability [6,12-14]. Hyperthyroidism is implicated as a predisposing factor for CVST. However, to date only several small studies have directly investigated the association between hyperthyroidism and CVST. Rau, et al. reported a case of Graves' disease with CVST presenting with headache and general weakness in an elderly man [8]. He exhibited a high level of fibrinogen, low protein $C$ activity, and atrial fibrillation [8]. Verberne, et al. reported the case of Graves' disease with CVST presenting as a viral encephalitis in a young woman through a factor VIII-mediated hypercoagulability [9]. Grien, et al. reported two cases of Graves' disease complicated by pulmonary embolism. Of these patients, a young woman showed an increased level of coagulation factor VIII [15]. Systematic literature review reported that the most frequently involved sites was cerebral venous veins, and over $60 \%$ of these cases reported an additional thrombophilic risk factor such as factor V Leiden mutation or protein C deficiency [14].

Although the precise mechanism underlying CVST or other thromboembolic events in Graves' disease remains unclear, several possibilities have been suggested. These include hypercoagulation, venous stasis, and abnormalities of the venous walls $[5,6,16]$. Many abnormalities of blood coagulation during thyrotoxic state have been described. Patients with hyperthyroidism had a shortened activated partial thromboplastin time, higher fibrinogen levels, increased levels of factor VIII and homocysteine, and decreased fibrinolytic activity during thyrotoxicosis in the previous studies [7-9,16]. Increased fibrinogen levels and reduced levels of protein $C$ were also associated with CVST development in Graves' disease patients [8]. The factor $\mathrm{V}$ Leiden mutation has been found in another case of thyrotoxic patient with CVST $[17,18]$. Protein C inhibits coagulation by inactivating factors VIIla and Va. Patients with protein $C$ deficiency may be at increased risk of thromboembolic events [8]. Apart from such changes in the coagulation system, several inherited or acquired risk factors for thrombosis are known in thyrotoxic patients [17]. Thyrotoxic state could induce vascular endothelial dysfunction [17], and venous stasis caused by goiter could affect CVST development [7]. In our case, thrombophilic features were normal and no other risk factor for venous thrombosis was identified. Furthermore, the goiter was not large enough that it could trigger venous stasis. Overt hyperthyroidism is associated with thromboembolic events through several mechanisms evidenced by several case series.

Diagnostic radiological findings in patients with CVST include the following: venous sinus thrombosis can be identified as a hyperdensity lesion of the affected sinus for the first 7-14 days on non-enhanced CT images. Following contrast administration, CVST presents as a filling defect in a sinus, and patients with involvement of the sagittal sinus and transverse sinus typically show the 'empty delta sign' and dense vein/triangle sign with or without cord sign respectively. Reportedly, CT venography shows a sensitivity of $95 \%$ in these cases. MRI can help in visualization of the clot as well as the sequelae. The clot shows variable signal intensity based on its stage (acute-to-chronic stage). During the acute stage, the clot appears isointense on T1WI and hypointense on $\mathrm{T} 2 \mathrm{WI}$, and during the subacute stage the clot appears as a hyperintense lesion on T1WI. Notably, clots can be easily detected as a dark signal within areas of hemorrhage (typically described as blooming artifacts) on $\mathrm{T}^{*} \mathrm{GRE}$ or susceptibility images. Venous infarction can be identified on DWI. Contrast-enhanced MR or MR venography shows greater sensitivity in detecting thrombosis, which presents as a venous filling defect in patients with CVT.

The patient described in this case report presented with CVST without a medical history to support this diagnosis. Diagnosis of Graves' disease concomitant with CVST was established only at the time of her current admission. The association between CVST and 
thyrotoxicosis was first described by Kaliebe in 1913 [19] and by Doyle in 1927 [20]; at least 23 cases have been reported thereafter [21-24]. A hypercoagulable state induced by high circulating levels of thyroid hormones is the likely mechanism contributing to the pathophysiology in these cases [17]. The combined effects of hyperthyroidism on procoagulant and fibrinolytic activity increase the risk of venous thrombosis. Currently, venous thrombosis is accepted as a 'multicausal' disease because several genetic and environmental conditions work together [25].

Although initial laboratory investigations revealed poorly controlled thyroid hormone levels indicating thyrotoxicosis, the diagnosis of CVST was delayed in this patient until confirmatory MR venography was performed. Any further delay in diagnosis could have led to irreversible neurological injury even with optimal treatment. This case emphasizes the importance of careful evaluation for early diagnosis of venous thrombosis in young adults with hyperthyroidism presenting with unexplained neurological symptoms. Clinicians should be aware that further evaluation to confirm CVST should be considered with CT or MR angiography with venous phase and blood-sensitive MR sequences, such as $T 2^{*}$ GRE or susceptibility weighted imaging in patients with a suspicious hyperdensity or the empty delta sign/cord sign/dense vein sign in the cerebral venous sinuses on brain CT.

\section{Conclusion}

In conclusion, previously published data strongly suggest that hyperthyroidism should be considered an important risk factor for CVST. In contrast to several other risk factors for CVST, the majority of thyroid disorders are treatable in a simple and effective manner. Comprehensive evaluation is warranted for prompt diagnosis of CVST in patients with hyperthyroidism presenting with unexplained neurological symptoms. If this potential causal relationship is supported by larger observational studies, this may have significant clinical implications, particularly for prevention and treatment. Therefore, we suggest considering thyroid dysfunction as a relevant risk factor for CVST, and propose the evaluation of thyroid parameters in patients with CVST by default. Future large observational studies are needed to provide further information about the association between hyperthyroidism and coagulationfibrinolytic abnormalities.

\section{Conflict of Interests}

None declared.

\section{References}

1. Einhäupl K, Bousser MG, de Bruijn SF, Ferro JM, Martinell I, et al. (2006) EFNS guideline on the treatment of cerebral venous and sinus thrombosis. Eur J Neurol 13: 553-559.

2. Allroggen H, Abbott RJ (2000) Cerebral venous sinus thrombosis. Postgrad Med J 76: 12-15.
3. Ferro JM, Canhão $P$, Stam J, Bousser MG, Barinagarrementeria $F$ (2004) Prognosis of cerebral vein and dural sinus thrombosis: Results of the International study on cerebral vein and dural sinus thrombosis (ISCVT). Stroke 35: 664-670.

4. Saposnik G, Barinagarrementeria F, Brown RD Jr, Bushnell CD, Cucchiara B, et al. (2011) Diagnosis and management of cerebral venous thrombosis: A statement for healthcare professionals from the American Heart Association/ American Stroke Association. Stroke 42: 1158-1192.

5. Squizzato A, Gerdes VE, Brandjes DP, Büller HR, Stam $\mathrm{J}$ (2005) Thyroid diseases and cerebrovascular disease. Stroke 36: 2302-2310.

6. Erem C, Ersoz HO, Karti SS, Ukinç K, Hacihasanoglu A, et al. (2002) Blood coagulation and fibrinolysis in patients with hyperthyroidism. J Endocrinol Invest 25: 345-350.

7. Siegert CE, Smelt AH, de Bruin TW (1995) Superior sagittal sinus thrombosis and thyrotoxicosis. Possible association in two cases. Stroke 26: 496-497.

8. Ra CS, Lui CC, Liang CL, Chen HJ, Kuo YL, et al. (2001) Superior sagittal sinus thrombosis induced by thyrotoxicosis. Case report. J Neurosurg 94: 130-132.

9. Verberne HJ, Fliers E, Prummel MF, Stam J, Brandjes DP, et al. (2000) Thyrotoxicosis as a predisposing factor for cerebral venous thrombosis. Thyroid 10: 607-610.

10. Colleran KM, Ratliff DM, Burge MR (2003) Potential association of thyrotoxicosis with vitamin $B$ and folate deficiencies, resulting in risk for hyperhomocysteinemia and subsequent thromboembolic events. Endocr Pract 9: 290-295.

11. Coutinho JM, Zuurbier SM, Stam J (2014) Declining mortality in cerebral venous thrombosis: A systematic review. Stroke 45: 1338-1341.

12. Erem C (2009) Coagulation and fibrinolysis in thyroid dysfunction. Endocrine 36: 110-118.

13. Erem C (2011) Thyroid disorders and hypercoagulability. Semin Thromb Hemost 37: 17-26.

14. Franchini $M(2006)$ Hemostatic changes in thyroid diseases: Haemostasis and thrombosis. Hematology 11: 203-208.

15. Grine S, Charfi N, Kamoun M, Mnif F, Naceur BB, et al. (2013) Hyperthyroidism: A rare cause of pulmonary embolism: Report of two cases. Indian J Endocrinol Metab 17: 1104-1107.

16. Lippi G, Franchini M, Targher G, Montagnana M, Salvagno $\mathrm{GL}$, et al. (2009) Hyperthyroidism is associated with shortened APTT and increased fibrinogen values in a general population of unselected outpatients. J Thromb Thrombolysis 28: 362-365.

17. Bensalah $M$, Squizzato $A$, Ould Kablia $S$, Menia $H$, Kemali $Z$ (2011) Cerebral vein and sinus thrombosis and hyperthyrodism: A case report and a systematic review of the literature. Thromb Res 128: 98-100.

18. Molloy E, Cahill M, O'Hare JA (2003) Cerebral venous sinus thrombosis precipitated by Graves' disease and Factor $V$ Leiden mutation. Ir Med J 96: 46-47.

19. Kaliebe H (1913) Autochthone sinusthrombose bei einem falle von morbus basedow und tabes. Med Klin 9: 19291932.

20. Doyle JB (1927) Obstruction of the longitudinal sinus. Arch Neurol Psychiatry 18: 374-382.

21. Hermans E, Mariën P, De Deyn PP (2011) Sinus 
sigmoideus thrombosis secondary to graves' disease: A case description. Case Rep Neurol 3: 203-209.

22. Hwang JU, Kwon KY, Hur JW, Lee JW, Lee HK (2012) The role of hyperthyroidism as the predisposing factor for superior sagittal sinus thrombosis. J Cerebrovasc Endovasc Neurosurg 14: 251-254.

23. Merino $M$, Guijarro MG, Iglesias $P$, Aladro $Y$, Montero $P$ (2012) Thyrotoxicosis and cerebral venous sinus thrombosis, causality or chance alone? Endocrinol Nutr 59: 462-463.
24. Migeot M, Rutgers MP, Gille M (2013) Puerperal cerebral sinus venous thrombosis and acute hyperthyroidism in Graves' disease. Acta Neurol Belg 113: 331-333.

25. Rosendaal FR (1999) Venous thrombosis: A multicausal disease. Lancet 353: 1167-1173. 